\title{
Estimating the Prevalance of Facial Asymmetry in the South Indian Population
}

\author{
Mary Sheloni Missier ${ }^{1 *}$, Dr. Ashwin Mathew George ${ }^{2}$
}

\begin{abstract}
${ }^{1}$ Post Graduate, Department of Orthodontics, Saveetha Dental College and Hospitals, Saveetha Institute of Medical \& Technical Sciences, 162, Poonamallee High Rd, Velappanchavadi, Chennai, Tamil Nadu 600077, India

${ }^{2}$ Professor, Department Of Orthodontics, Saveetha Dental College and Hospitals, Saveetha Institute of Medical \& Technical Sciences, 162, Poonamallee High Rd, Velappanchavadi, Chennai, Tamil Nadu 600077, India
\end{abstract}

DOI: $10.36347 /$ sjds.2021.v08i01.003

| Received: 26.12.2020 | Accepted: 02.01.2021 | Published: 05.01.2021

*Corresponding author: Mary Sheloni Missier

Abstract Original Research Article

Face is the part of the body where a no of emotions of humans are being expressed. It is said that the right side and the left side of the face are not similar. All humans have mild facial asymmetry which is natural and do not require any treatment whereas severe asymmetry required the assistance of orthodontic and surgent to encounter their problem. There are various diagnostic methods to diagnose facial asymmetry some of the diagnostic method of clinical examination, extraoral photographs, various radiographs such as PA ceph, temporomandibular, submento vertex radiographs some of the other supplemental diagnostic aids. It helps us in the diagnoses of facial asymmetry but these require additional cost, setup therefore in this study we demonstrate a simpler method for diagnoses of asymmetry using frontal photograph to analyse the soft tissue facial asymmetry among south Indian population. This study was done with the extraoral frontal photograph of 50 subjects of age group 15 to 30 years of age. The face was divided into lateral, median and middle part and measured with vernier caliper and statistically analysed by independent $t$ test. The results were tabulated and it was found that the right side of the face is not symmetrical to the left side of the face.

Keywords: Asymmetry, extraoral photograph, facial midline.

Copyright $\odot 2021$ The Author(s): This is an open-access article distributed under the terms of the Creative Commons Attribution 4.0 International License (CC BY-NC 4.0) which permits unrestricted use, distribution, and reproduction in any medium for non-commercial use provided the original author and source are credited.

\section{INTRODUCTION}

The term symmetry is defined as the equal proportions of all the parts in term of size, shape and position. It is always known that the human body can be divided into identical halves (the right side of the body is not identical to the left side). Some changes may occur resulting in asymmetry due to some environmental or biological disturbances. Face is the part of the body where a no of emotions of humans are being expressed. It is said that the right side and the left side of the face are not similar. Epidemiological studies states that the prevalence of asymmetry ranges from $12 \%$ to $37 \%$ in united states, $23 \%$ in Belgium, $21 \%$ in Hong Kong [6-10]. All humans have mild facial asymmetry which is natural and do not require any treatment whereas sever asymmetry required the assistance of orthodontic and surgent to encounter their problem, There are various etiologic factors which vary depending upon various authors Chia et al., [1] stated that asymmetry could result due to pathological, traumatic, functional or developmental factors. Haraguchi et al., [2], he claims that hereditary is also one of the causative factor for facial asymmetry.
Cheong and Lo [3], they categorized the causative factor for facial asymmetry under three sub-divisions such as congenital, acquired and developmental. Lundström et al., [4], states that facial asymmetry could result due to genetic or non genetic factors. Bishara et al., [5], classified asymmetry as dental, skeletal, functional or muscular.

There are various diagnostic methods to diagnose facial asymmetry some of the diagnostic method of clinical examination, extraoral photographs. With recent advancement in the field of radiography, various radiographs such as PA ceph, temporomandibular, submento vertex radiographs some of the other supplemental diagnostic aids. It helps us in the diagnoses of facial asymmetry but these require additional cost, setup therefore in this study we demonstrate a simpler method for diagnoses of asymmetry using frontal photograph.

\section{MATERIAL AND METHODS}

This study was performed on 50 subjects reporting to the Department of Orthodontics, Saveetha 
Dental College, Chennai within the age group of 15 to 30 years.

\section{PHOTOGRAPHIC TECHNIQUE}

Frontal view photographs in natural head position (NHP) were taken using the digital camera under standardised conditions. The canon digital camera was then placed at a distance of $90 \mathrm{cms}$ and parallel to the floor, at the same level as the eye of the subject, fitted on a standard adjustable tripod.

The digital photographs were transferred from the camera to the computer to analysis the facial asymmetry. Along with the vertical lines in the rule of fifth, the midline was also added. The midline was constructed as a vertical line passing through glabella and subnasale. The following divisions were made on the photographs as seen in the figure

1. Postaurale- exocanthion (pa r-ex r) lateral Part,

2. Exocanthion- endocanthion (ex r-en r), middle Part,

3. Endocanthion- midline (en $\mathrm{r}-\mathrm{m}$ ) median part

The photographs were opened in software MWSNAP 3.0. The distances in the different parts were measured using vernier caliper and statistically analysed using independent $\mathrm{t}$ test.

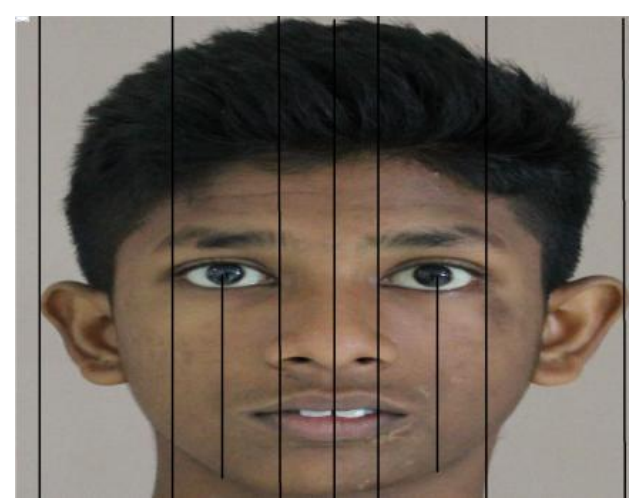

Figure-1

\section{RESULTS}

The frontal photographs of the subjects were used to to estimate the prevalence of facial asymmetry in the south Indian population, the face was divided into three parts and the distance between the different parts were measured using vernier caliper and statistically analysed using independent $t$ test. Based on the results of the independent $t$ test, there was significant difference between the right and the left side of the face which shows that the right side and the left side of the face is not symmetrical.

Table-1

\begin{tabular}{|l|l|l|l|l|}
\hline \multicolumn{5}{|c|}{ Independent Samples Test } \\
\hline \multicolumn{2}{|c|}{} & t-test for Equality of Means \\
\cline { 2 - 5 } & Sig. (2-tailed) & Mean Difference & Std. Error Difference \\
\hline \multirow{2}{*}{ Measure } & Equal variances assumed & .050 & .780 & .394 \\
\cline { 2 - 5 } & Equal variances not assumed & .050 & .780 & .394 \\
\hline
\end{tabular}

\section{INTERPRETATION}

$\mathrm{H}_{0}$ : There is no significant difference between $\mathrm{r} 1$ and 11

$\mathrm{H}_{\mathrm{a}}$ : There is significant difference between $\mathrm{r} 1$ and 11

Sig value is .050 , ie $.050<=.050, \mathrm{H}_{0}$ is not accepted and $\mathrm{H}_{\mathrm{a}}$ is accepted.

Therefore there is significant difference between $\mathrm{r} 1$ and 11 .

Table-2

\begin{tabular}{|l|l|l|l|l|}
\hline \multicolumn{5}{|c|}{ Independent Samples Test } \\
\hline \multirow{2}{|c|}{} & t-test for Equality of Means \\
\cline { 2 - 5 } \multicolumn{2}{|c|}{ Measure } & Sig. (2-tailed) & Mean Difference & Std. Error Difference \\
\cline { 2 - 5 } & Equal variances assumed & .431 & .500 & .632 \\
\cline { 2 - 5 } & Equal variances not assumed & .431 & .500 & .632 \\
\hline
\end{tabular}

\section{INTERPRETATION}

$\mathrm{H}_{0}$ : There is no significant difference between $\mathrm{r} 2$ and 12

$\mathrm{H}_{\mathrm{a}}$ : There is significant difference between $\mathrm{r} 2$ and 12

Sig value is .431 , ie $.431<=.050, \mathrm{H}_{0}$ is not accept and $\mathrm{H}_{\mathrm{a}}$ is accepted

Therefore there is significant difference between $\mathrm{r} 2$ and 12 . 
Mary Sheloni Missier \& Ashwin Mathew George., Sch J Dent Sci, Jan, 2021; 8(1): 14-18

Table-3

\begin{tabular}{|c|l|l|l|l|}
\hline \multicolumn{5}{|c|}{ Independent Samples Test } \\
\cline { 3 - 5 } \multicolumn{2}{|c|}{} & t-test for Equality of Means \\
\hline \multirow{2}{*}{ Measure } & Sig. (2-tailed) & Mean Difference & Std. Error Difference \\
\cline { 2 - 5 } & Equal variances assumed & .418 & .650 & .799 \\
\cline { 2 - 5 } & Equal variances not assumed & .418 & .650 & .799 \\
\hline
\end{tabular}

\section{INTERPRETATION}

$\mathrm{H}_{0}$ : There is no significant difference between r3 and 13

$\mathrm{H}_{\mathrm{a}}$ : There is significant difference between $\mathrm{r} 3$ and 13

Sig value is .418 , ie $.418<=.050, \mathrm{H}_{0}$ is not accept and $\mathrm{H}_{\mathrm{a}}$ is accepted.

Therefore there is significant difference between $\mathrm{r} 3$ and 13 .

\section{DISCUSSION}

The asymmetry of the human face has been investigated using methods involving frontal facial photographs, posteroanterior cephalograms, and stereophotogrammetry [5-16]. The key for evaluating the facial asymmetry using one of these methods is defining the criteria for determining the facial midline. Because there is no absolute facial midline, we employed the line along glabella to subnasale, centers of the pupils of the eyes as landmarks for defining the facial midline, as well as the area of the head forward to the ears of the face. We assumed that proper visual recognition of an object in space on binocular vision is achieved according to a perpendicular bisector to a line connecting bilateral pupils. This bisector coincides with the direction of gravity and was defined as the facial midline [19]. Previous reports have suggested that facial asymmetry is likely to exhibit laterality [5-16]. The present study examined facial laterality from two perspectives: (1) which side of the hemiface is most likely to be wider and (2) to which side does the chin tend to deviate. The results indicated that $79.7 \%$ of subjects with facial asymmetry had a wider right hemiface and, concomitantly, that $79.3 \%$ of subjects with chin deviation showed left-sided laterality. Most of the studies examining differences in hemiface size have used relatively small samples of 100 or fewer. The lack of consistent agreement among the results of previous studies may reflect the inadequacy of these relatively small samples in detecting subtle differences in size between the left and the right hemiface. We found a consistent tendency for dominance of the right hemiface. As the growth stage proceeds, however, right-sided dominance becomes less frequent, whereas left-side dominance becomes more frequent. Mobility of facial expression also exhibits facedness [20, 21]. Most studies suggest that the left side of the face is more expressive of emotions [22-24]. Such a functional asymmetry in facial expression may have some relationship to the dimensional balance between the left and the right hemiface. While the proportion of subjects who exhibited no deviation at the menton decreased with age, the proportion of those having the left-sided deviation increased accordingly. In terms of skeletal pattern, no deviation at the menton was more frequently seen in subjects with the skeletal Class III malocclusion than in those with skeletal Class II malocclusion. Specifically, the proportions of the no-deviation, rightsided, and left-sided groups in the skeletal Class II subjects were consistent for all pubertal growth periods. In the skeletal Class I group, however, the proportion of subjects with no significant jaw deviation decreased with age, whereas the proportion of those with leftsided jaw deviation increased. In this group, the proportion of the subjects exhibiting right-sided jaw deviation was similar between different growth stages. In the skeletal Class III group, the proportion of subjects without chin deviation also decreased throughout the pubertal growth period, and the proportions of both those with left-sided deviation and those with right-sided deviation tended to increase. These findings suggest that, overall, the proportion of subjects with jaw deviation at the menton remains unchanged during the pubertal growth period because those with skeletal Class II jaw relationship are likely to show relatively less growth of the mandible, even during the pubertal growth period. In contrast, skeletal Class III patients generally exhibit greater growth and are more likely to be affected by postnatal, environmental influences because of the relatively longer jaw growth period. Previous studies [5, 6, 25, 26] have discussed possible causes of facial laterality. Most have concluded that environmental influences were the most likely cause. Habitual chewing on one side has been reported to lead to increased skeletal development on the ipsilateral side [5]. Others have also discussed the possibility that such laterality is simply a response of functional adaptation to asymmetrical masticatory activity [13]. On the other hand, other studies [27] that have investigated facial asymmetry have emphasized the innate functional and structural differences between the cerebral hemispheres, suggesting that it would not be surprising if the normal asymmetry of the human face primarily originated from brain and skull base asymmetry. According to a recent report [15], lateral displacement of the cephalometric menton toward the left side of the face is found more frequently than right sided deviation. The study also documented, however, that subjects who had received chin cup treatment or had exhibited TMJ symptoms and/or reported a history of maxillofacial injury showed a higher proportion of right-sided chin deviation at menton when compared with those who had not experienced those factors. It was therefore suggested that these postnatal factors are not the causes of 
directional uniqueness in menton deviation. Given the possibility that the right-side hemiface grows wider than its counterpart because of postnatal factors, such as more use of a habitually preferred chewing side, it would be reasonable to assume that the proportion of individuals who show facial laterality toward the right side increases during the pubertal growth period. In this study the proportion of subjects with right-sided laterality decreases with age while the proportion of those with left-sided laterality increases. It can be speculated that the laterality in normal asymmetry consistently found in human faces may likely be induced by prenatal rather than postnatal factors, such as a functional bias induced by facedness or lateral preference in mastication. Finally, the results of the present study may help to explain why photographic frontal views of the human face that are artificially manipulated to reflect complete symmetry appear so strange to the viewer's eyes. The perfectly symmetric face differs sharply from the normal asymmetric face that is so familiar to us and thus may seem unnatural. Kowner et al., [30] in his study analyzed the effect of subject's and stimulus person's sex on attributions of emotions and personality. In the absence of any significant differences in the previous analysis, we wanted to demonstrate that the set of stimuli was capable of producing attributional differences. Indeed, we found significant differences between the ratings of the male and female stimulus person, which are probably caused by the specific characteristics of these two groups. The females were indeed younger, obviously looked more feminine and because of genderrole expectation was rated as more passive. The sex difference found between the subjects concerns attractiveness evaluation. Females rated the stimulus persons higher than the males.

Severt and Proffit [7] conducted a research with 1460 patients at the University of North Carolina and reported that $34 \%$ of individuals were found with a prevalence of facial asymmetry, with deviation of the chin being the most remarkable feature of asymmetry. Deviation of the chin was present in $74 \%$ of asymmetrical patients, with a frequency of lateral guidance of the upper and midface equal to $5 \%$ and $36 \%$, respectively. Therefore, deviation of the lower face is more frequent and greater in length than that of the upper and midface. A possible explanation would be the longer mandibular growth periods, in addition to the maxilla being rigidly attached to the stable region of synchondroses at the cranial base [11]. Most studies on asymmetry claim that lateral guidance is most predominant on the left side of the face $[7,26,28]$ with equal distribution among males and females [6, 26, 27]. This occurrence could be explained by the dominant growth potential on the right side of the face, particularly considering the larger dimensions of the skull and the brain of individuals on the right side. Another potential innate mechanism causative of lateral guidance of the face might be related to the imbalanced development of neural crest cells. It has been speculated that neural crest cell migration happens earlier on the right side and tends to be delayed on the left side [11, 4, 28].

Lundstrom pointed out that detailed esthetic judgement can only be made by viewing patients from the front in conversation, various facial expressions and smiling. Hence in our study, we took frontal photographs of the subjects in different positions for better visual perception and application to denture esthetics [4]. As the Interpupillary line was one of the reference lines in the study, it was sometimes difficult to locate the center of the pupil on the image of the subject by inspection because the upper eyelid was superimposed on part of the pupil area especially when the subject was smiling and both the eyelids tended to close. This study used the flash reflection from the pupil area, which was seen as a clear white area on the centre of pupil. This made it easier to locate the centre of pupil even when the eyelids overlapped part of the pupil. For this purpose we used a mirror on top of the camera as an external source of eye reference. The subjects tended to look up more when the mirror was used as a reference [3]. The occlusal plane position is the foundation of clinical treatment and one of the most important criteria used to judge the degree of treatment success. In a study they used the Fox plane and the wooden spatula (IC) to represent the cant of occlusal plane. The Fox plane and the IC do not coincide with the true horizontal suggestive of a definite canting of the occlusal plane, which varies from individual to individual. Due to these individual variations, a standardized approach in locating the occlusal plane may result in less than ideal esthetics in the final restoration [5]. According to the studies done by Shah and joshi [12], Peck and Peck [18], the right side was found to be significantly larger than the left side.

Kowner and Ogawa [28] found this sex difference in an earlier study and suggested it may be the result of the traditional gender-role expectation that prevails in Japan. That is, women are expected to exhibit servile manners and to show compassion toward others and therefore they tend to rate them higher than male. In our study we found that the right side of the face is not symmetrical to the left side of the face.

\section{CONCLUSION}

In our study it was found that the right and left side of face was not symmetrical.

\section{REFERENCE}

1. Chia MS, Naini FB, Gill DS. The aetiology, diagnosis and management of mandibular asymmetry. Ortho Update. 2008; 1(1):44-52.

2. Haraguchi S, Iguchi Y, Takada K. Asymmetry of the face in orthodontic patients. Angle Orthod. 2008 May; 78(3):421-6. 
Mary Sheloni Missier \& Ashwin Mathew George., Sch J Dent Sci, Jan, 2021; 8(1): 14-18

3. Cheong YW, Lo LJ. Facial asymmetry: etiology, evaluation, and management. Chang Gung Med J. 2011 Jul-Aug; 34(4):341-51.

4. Lundström A. Some asymmetries of the dental arches, jaws, and skull, and their etiological significance. Am J Orthod. 1961; 47(2):81-106.

5. Bishara SE, Burkey PS, Kharouf JG. Dental and facial asymmetries: a review. Angle Orthod. 1994; 64(2):89-98.

6. Sheats RD, McGorray SP, Musmar Q, Wheeler TT, King GJ. Prevalence of orthodontic asymmetries. Semin Orthod. 1998 Sep; 4(3):13845.

7. Severt TR, Proffit WR. The prevalence of facial asymmetry in the dentofacial deformities population at the University of North Carolina. Int J Adult Orthodon Orthognath Surg. 1997; 12(3):171-6.

8. Bailey LJ, Haltiwanger LH, Blakey GH, Proffit WR. Who seeks surgicalorthodontic treatment: a current review. Int $\mathbf{J}$ Adult Orthodon Orthognath Surg. 2001 Winter; 16(4):280-92.

9. Willems G, De Bruyne I, Verdonck A, Fieuws S, Carels C. Prevalence of dentofacial characteristics in a Belgian orthodontic population. Clin Oral Investig. 2001 Dec; 5(4):220-6.

10. Samman N, Tong AC, Cheung DL, Tideman H. Analysis of 300 dentofacial deformities in Hong Kong. Int J Adult Orthodon Orthognath Surg. 1992; 7(3):181-5.

11. Good S, Edler R, Wertheim D, Greenhill D. A computerized photographic assessment of the relationship between skeletal discrepancy and mandibular outline asymmetry. Eur J Orthod. 2006; 28:97-102.

12. Shah SM, Joshi MR. An assessment of asymmetry in the normal craniofacial complex. Angle Orthod. 1978; 48:141-148.

13. Burke PH. Growth of the soft tissues of middle third of the face between 9 and 16 years. Eur J Orthod. 1979; 1:1-13.

14. Koff E, Borod JC, White B. Asymmetries for hemiface size and mobility. Neuropsychologia. $1981 ; 19: 825-830$.
15. Farkas LG, Cheung G. Facial asymmetry in healthy North American Caucasians. An anthropometrical study. Angle Orthod. 1981; 51:70-77.

16. Koff E, Borod J, Strauss E. Development of hemiface size asymmetry. Cortex. 1985; 21:153156.

17. Ferrario VF, Sforza C, Miani A, Tartaglia G. Craniofacial morphometry by photographic evaluations. Am J Orthod Dentofacial Orthop. 1993; 103:327-337.

18. Peck S, Peck L, Kataja M. Skeletal asymmetry in esthetically pleasing faces. Angle Orthod. 1991; 61:43-48.

19. Ferrario VF, Sforza C, Miani A, Serrao G. A three dimensional evaluation of human facial asymmetry. J Anat. 1995; 186:103-110.

20. Vig PS, Hewitt AB. Asymmetry of the human facialskeleton. Angle Orthod. 1975; 45:125-129.

21. Chebib FS, Chamma AM. Indices of craniofacial asymmetry. Angle Orthod. 1981; 51:214-226.

22. Haraguchi S, Takada K, Yasuda Y. Facial asymmetry in patients with skeletal Class III deformity. Angle Orthod. 2002; 72:28-35.

23. Murata M. Characteristics of pubertal growth in Japanese children from the standpoint of skeletal growth. Acta Pediatr Jpn. 1992; 34:236-242.

24. Iizuka T. Studies for facial growth of Japanese children using roentgen cephalography [in Japanese]. J Stomatol Soc Jpn. 1958; 25:260-272.

25. Hess BJ. Vestibular signals in self-orientation and eye movement control. News Physiol Sci. 2001; 16:234-238.

26. Smith WM. Hemispheric and facial asymmetry: gender differences. Laterality. 2000; 5:251-258.

27. Hardie S, Hancock P, Rodway P, Penton-Voak I, Carson D, Wright L. The enigma of facial asymmetry: is there a gender-specific pattern of facedness? Laterality. 2005; 10:295-304.

28. Kowner R, Ogawa T. The role of raters' sex, personality, and appearance in judgments of facial beauty. Perceptual and Motor Skills. 1995 Aug;81(1):339-49. 